\section{Nithsdale Schizophrenia Surveys 20}

\author{
Cognitive function in a catchment-area-based population \\ of patients with schizophrenia
}

\section{KELLY, V. SHARKEY, G. MORRISON, J. ALLARDYCE and R. G. MCCREADIE}

\section{Background Cognitive deficits are a core aspect of schizophrenia but there has been no study of cognitive function in a catchment-area-based population of patients with schizophrenia.}

\begin{abstract}
Aims To assess cognitive function in a population of patients with schizophrenia, and relate it to community functioning.
\end{abstract}

Method All patients with schizophrenia in Nithsdale, south-west Scotland, were identified $(n=182)$. Measures of assessment were: National Adult Reading Test (NART), Mini-Mental State Examination (MMSE), Rivermead Behavioural MemoryTest (RBMT), Executive Interview (EXIT), FAS Verbal Fluency and Health of the Nation Outcome Scales (HoNOS).

Results We assessed 138 patients, mean age 48 years (standard deviation (s.d.) 15). Only 14\% were in-patients. The mean premorbid IQ as assessed by NART was 98 (s.d. 14); 15\% of patients had significant global cognitive impairment (MMSE); $81 \%$ had impaired memory (RBMT); 25\% had executive dyscontrol (EXIT); and 49\% had impaired verbal fluency (FAS). Scores on the functional impairment sub-scale of HoNOS correlated with all measures of cognitive impairment.

Conclusions Cognitive dysfunction is pervasive in a community-based population of patients with schizophrenia.

Declaration of interest None.
It is now generally accepted that cognitive deficits are a core aspect of the schizophrenic illness (Goldberg et al, 1987; Frith et al, 1991). The consequences of cognitive dysfunction for community functioning have been reviewed relatively recently (Green, 1996), and Golberg et al (1993) have shown that it is likely to limit patients' rate of rehabilitation. However, the exact nature and extent of neuropsychological deficits in acute and chronic schizophrenia remain uncertain. Schizophrenia may be associated with global intellectual impairment (Liddle \& Crow, 1984; Frith et al, 1991); memory may be disproportionately affected (McKenna et al, 1990; Saykin et al, 1991), as may executive function (Goldberg et al, 1987). Previous studies have reported on small samples of people examined by an extensive neuropsychological battery (Saykin et al, 1991), or on larger samples with fewer tests (McKenna et al, 1990). In our study, the first of its kind, we report on cognition in a catchment-area-based population of patients with schizophrenia and examine the relationship between cognitive function and community functioning.

\section{METHOD}

\section{Patients}

The identification of the schizophrenic population has been described in detail previously (McCreadie, 1982; Kelly et al, 1998). Briefly, repeat censuses in Nithsdale (population 57 000) in south-west Scotland have on many occasions over the years identified all patients with schizophrenia. Patients in the present study were identified on 1 April 1998. They included all inpatients, day patients and out-patients known to Crichton Royal Hospital on the census date who had an ICD-10 diagnosis of schizophrenia (World Health Organization, 1992) and whose home address was in Nithsdale. General practitioners
(GPs) in the Nithsdale area were given a list of patients with schizophrenia in their practice and asked to update it; all general practitioners replied. In addition, community psychiatric nurses, voluntary agencies and social workers were asked to identify any other patients with schizophrenia. Over the years, this 'key informant' method has allowed us to identify, trace and interview such patients in Nithsdale.

The ICD-10 diagnosis of schizophrenia is broad; however, a 1997 Nithsdale study (McCreadie et al, 1997) showed that $87 \%$ of patients with a clinical diagnosis of schizophrenia also fulfilled OPCRITderived DSM-III-R criteria (McGuffin et al, 1991).

The census identified 182 patients, 96 $(53 \%)$ male and $86(47 \%)$ female. Of these, $9 \%$ were long-stay and $5 \%$ acute inpatients, $20 \%$ were day patients, and $34 \%$ out-patients, $17 \%$ mainly had contact with the community psychiatric nurse and $15 \%$ had contact with the GP only. As a prevalence study, the population included patients whose illness varied greatly in chronicity and severity. No patients had received electroconvulsive therapy in the preceding 12 months. Informed consent was obtained for all subjects before participation.

\section{Assessment of cognitive function}

Measures were chosen for their shortness, ease of use and acceptability to patients. Cognition was assessed using a battery of five cognitive measures.

(a) The National Adult Reading Test (NART), which gives an estimate of premorbid IQ (Nelson, 1982). The NART has been assessed in patients with schizophrenia and been shown to be a valid measure of premorbid IQ (Crawford, et al, 1992).

(b) The Mini-Mental State Examination (MMSE), a well-established screening test for cognitive impairment (Folstein et al, 1975). The MMSE has been used as a broad test of global cognitive function in schizophrenia and shown to be reliable and stable (Harvey et al, 1995). A score of $<24$ is indicative of significant global cognitive impairment.

(c) The Rivermead Behavioural Memory Test (RBMT), a measure of everyday memory (Wilson et al, 1989). The RBMT was initially designed for a 
Table I Demographic and clinical data and cognitive scores by gender

\begin{tabular}{|c|c|c|c|c|c|c|}
\hline & \multicolumn{3}{|c|}{ Male } & \multicolumn{3}{|c|}{ Female } \\
\hline & $n$ & Mean & s.d. & $n$ & Mean & s.d. \\
\hline Age (years) & 72 & 46 & 14 & 66 & 51 & 18 \\
\hline Age range (years) & 72 & $23-76$ & & 66 & $20-90$ & \\
\hline Age at onset of illness (years) & 72 & 27 & 9 & 66 & 29 & 13 \\
\hline NART IQ & 68 & 98 & 14 & 64 & 98 & 14 \\
\hline MMSE' & 72 & 27 & 4 & 66 & 26 & 4 \\
\hline $\mathrm{RBMT}^{\prime}$ & 72 & 7 & 3 & 63 & 6 & 3 \\
\hline $\mathrm{EXIT}^{2}$ & 72 & II & 7 & 65 & 12 & 7 \\
\hline FAS' $^{\prime}$ & 71 & $26 *$ & 13 & 65 & $21 *$ & 13 \\
\hline
\end{tabular}

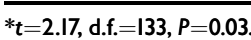

I. The lower the score, the greater the impairment.

2. The higher the score, the greater the impairment.

NART, National Adult Reading Test; MMSE, Mini-Mental State Examination; RBMT, Rivermead Behavioural Memory Test; EXIT, Executive Interview; FAS, Initial Letter Verbal Fluency Test.

brain-injured population, but has also been shown to be a useful measure of memory function in subjects with schizophrenia (McKenna et al, 1990). Two scores can be obtained: a screening score $(0-12)$ and a standardised profile score (0-24). Based on scores, patients can be categorised as having normal, poor, moderately impaired or severely impaired memory.

(d) The Executive Interview (EXIT) (Royall et al, 1992), a measure of the behavioural consequences of executive dyscontrol, which correlates well with established tests of executive functions such as the Wisconsin Card Sorting Test (Berg, 1948). It was designed for an elderly population but has been shown to be a reliable screening test in a schizophrenia group (Scully et al, 1997). It has 25 items, and the score ranges from 0 to 50 ; a score of $>15$ indicates executive dyscontrol.

(e) The Initial Letter Verbal Fluency Test (FAS), an assessment of executive (frontal) function and semantic memory store (a temporal lobe function) (Parker \& Crawford, 1992). In a timed test, the patient generates words beginning with the letters $\mathrm{F}, \mathrm{A}$ and $\mathrm{S}$. A score of $<30$ indicates reduced verbal fluency. The FAS and the Wisconsin Card Sorting Test have been shown to be the best validated tests of executive (frontal) function, and have been used widely with normal controls and with subjects with schizophrenia (Crawford et al, 1993).
All cognitive measures were administered by a research nurse (V.S.), trained in the use of the scales; a session lasted about 40 minutes.

Social disability and community functioning over the preceding 2 weeks were assessed by the Health of the Nation Outcome Scales (HoNOS; Wing et al, 1998). HoNOS is a simple, brief and clinically acceptable instrument based on an interview with the keyworker.

\section{Statistical analysis}

Differences between groups were examined by $t$-tests and analysis of variance (ANOVA); Pearson's $r$ was used to examine correlations.

\section{RESULTS}

\section{Educational history}

Fifty-nine per cent of the patients had completed secondary school education only, $23 \%$ had attended college or technical training, a further $11 \%$ had attended vocational training (e.g., for nursing or teaching) and $7 \%$ had started university education. Fifty-two per cent of the patients had obtained no qualifications, $32 \%$ had passed the secondary school examination, $9 \%$ had obtained college or technical qualifications and $7 \%$ had completed teacher or nurse training or obtained a university degree.

\section{Cognitive measures}

Cognition was assessed in 138 of 182 patients (response rate $76 \%$ ). There was no difference in age or gender between responders and non-responders: $52 \%$ of responders were male; demographic and clinical variables by gender are shown in Table 1.

One hundred and thirty-two patients completed the NART. The mean Wechsler Adult Intelligence Scale-Revised (WAIS$\mathrm{R}$; Wechsler, 1981) IQ generated from the NART error score was 98 (s.d. 14, range 69-126).

On the MMSE, $15 \%$ of patients showed significant global cognitive impairment; on the RBMT, $81 \%$ showed memory impairment; on the EXIT ( $n=137) 25 \%$ showed executive dyscontrol; and on the FAS $(n=136) \quad 49 \%$ had reduced verbal fluency. Figure 1 shows the distribution of scores for the MMSE $(n=138)$ and RBMT ( $n=135)$.

Table 1 shows cognitive measures for both genders; scores were similar except in the FAS, where men scored significantly higher.

\section{Cognition and age}

Cognition scores for patients in each of six age bands are shown in Table 2. Three women, aged 80, 89 and 90 years, were excluded from this analysis. There were no between-group differences in the NART IQ, but there were significant betweengroup differences in scores on the MMSE, RBMT, EXIT and FAS. Performance was poorest in the over-60 age groups.

\section{Community status}

The relationship between patients' community status (i.e., in-patient, out-patient, etc.) and cognitive results is shown in Table 3. There were significant betweengroup differences in scores on the MMSE, RBMT and EXIT. Long-stay in-patients scored lowest, and worse than patients of comparable age supported only by GP care.

\section{HoNOS}

Keyworkers of 47 of the patients were available for interview. The HoNOS has four sub-scales which assess behaviour, functional impairment, symptoms and social circumstances; a higher score indicates more disability. In the functional impairment sub-scale, the keyworkers rated $27 \%$ of the patients as having problems in the community owing to poor cognition (memory, orientation and understanding). There were significant correlations between 


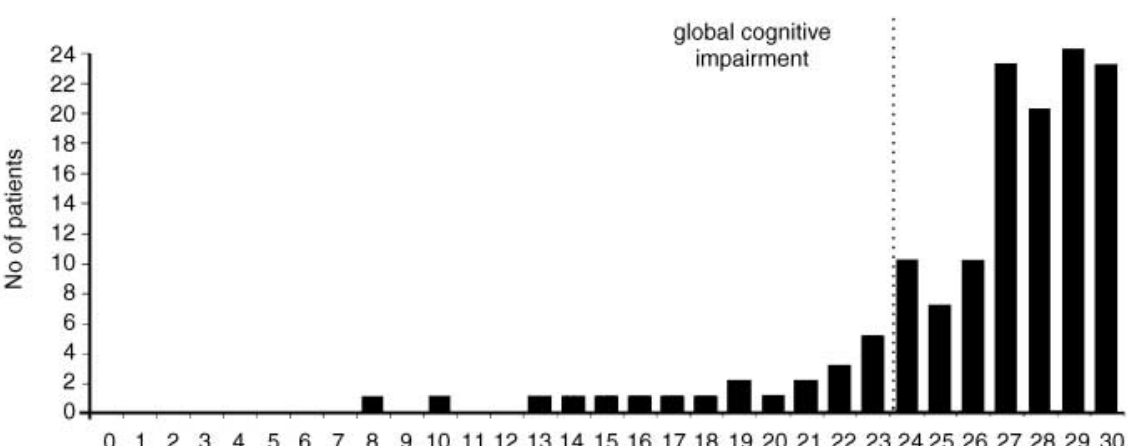

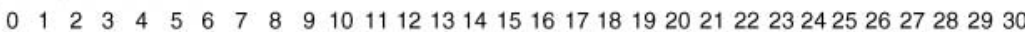
MMSE score

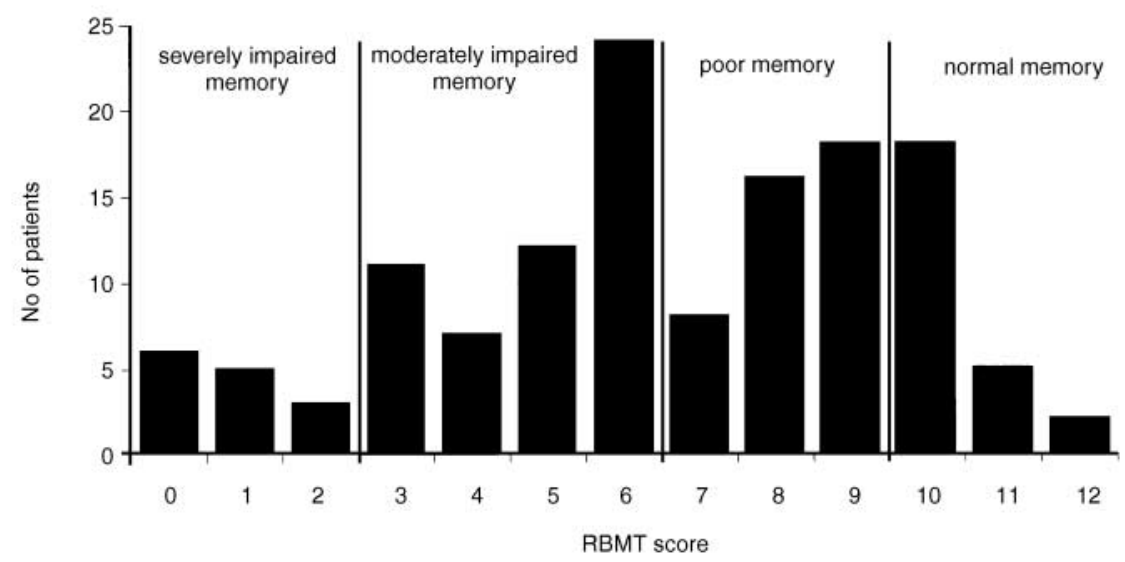

Fig. I Distribution of scores for Mini-Mental State Examination (MMSE) $(n=138)$ and Rivermead Behavioural Memory Test (RBMT) $(n=135)$.

cognitive measures and the functional impairment sub-scale of HoNOS; MMSE (Pearson's $r=-0.4, \quad P<0.01$ ), RBMT $(r=-0.5, \quad P<0.001), \quad$ EXIT $\quad(r=0.4$, $P<0.01)$ and FAS $(r=-0.4, P<0.01)$. Figure 2 shows the relationship between memory measured by RBMT and functional impairment measurement by HoNOS; the poorer the score on memory, the worse was the functional impairment.

\section{DISCUSSION}

We believe this is the first time that an attempt has been made to examine cognition in a whole catchment-area-based population of patients with schizophrenia. The clear limitations of assessment are those of time and the cooperation needed with each subject, which make testing people with schizophrenia very difficult. However, our study had a $76 \%$ response rate from a well-defined and wellcharacterised population; we believe our results are potentially generalisable.

\section{Cognitive dysfunction}

There was a high prevalence of cognitive dysfunction in our community-based population of patients with schizophrenia. Memory impairment was most obvious, with $81 \%$ affected. Fifteen per cent of the patients showed significant global cognitive impairment on the MMSE, while at least a quarter had executive (frontal) dysfunction. This high level of current cognitive dysfunction was present despite the fact that their premorbid IQ and schooling were predominantly normal. Other studies (e.g., Crawford et al, 1992) have found that people with schizophrenia perform similarly to control subjects on the NART. The only gender difference was in the FAS, where the women scored lower. This may be explained by the difference in mean age ( 5 years between the men and the women subjects); there is a high negative correlation between FAS performance and age (Crawford et al, 1993).

Our estimate of the prevalence and pervasiveness of memory problems in the Nithsdale population is almost identical to that of McKenna et al (1990), who investigated memory impairment in

Table 2 Cognitive measures by 10 -year age bands

\begin{tabular}{|c|c|c|c|c|c|c|c|c|c|c|c|c|}
\hline \multirow{2}{*}{$\begin{array}{l}\text { Age } \\
\text { bands }{ }^{4}\end{array}$} & \multirow[t]{2}{*}{$n^{\prime}$} & \multirow[t]{2}{*}{ Male/female ratio } & \multicolumn{2}{|c|}{ NART IQ } & \multicolumn{2}{|c|}{ MMSE $^{2}$} & \multicolumn{2}{|c|}{$\mathrm{RBMT}^{2}$} & \multicolumn{2}{|c|}{$\mathrm{EXIT}^{3}$} & \multicolumn{2}{|c|}{ FAS $^{2}$} \\
\hline & & & Mean & (s.d.) & Mean & (s.d.) & Mean & (s.d.) & Mean & (s.d.) & Mean & (s.d.) \\
\hline $20-29$ & 17 & $7 / 10$ & 97 & (9) & 28 & (2) & 7 & (2) & 7 & (3) & 31 & (II) \\
\hline $30-39$ & 31 & $19 / 2 \mid$ & 100 & (II) & 28 & (2) & 8 & $(2)$ & 8 & (5) & 27 & (II) \\
\hline $40-49$ & 29 & $19 / 10$ & 97 & (13) & 26 & (3) & 7 & (3) & 12 & (7) & 25 & (13) \\
\hline $50-59$ & 28 & $16 / 12$ & 102 & (16) & 27 & (2) & 8 & (2) & 10 & (5) & 24 & (9) \\
\hline $60-69$ & 16 & $4 / 12$ & 92 & (3) & 23 & (5) & 4 & (3) & 18 & (7) & 14 & (II) \\
\hline $70-79$ & 14 & $7 / 7$ & 94 & (20) & 23 & (6) & 4 & (3) & 16 & (7) & 19 & (14) \\
\hline
\end{tabular}

I. $n$ in different age bands for different tests varies slightly, as not all patients completed all tests (see Table I).

2. The lower the score, the greater the impairment.

3. The higher the score, the greater the impairment.

4. ANOVA results by 10 -year age bands: NART IQ: $F=1.21$, d.f. $=5, P=0.31$; MMSE: $F=10.02$, d.f. $=5, P<0.001$; RBMT: $F=9.43$, d.f. $=5, P<0.001$; EXIT: $F=I 1.09$, d.f. $=5, P<0.001$; $F A S:$ $F=4.42$, d.f. $=5, P=0.00$ l.

NART, National Adult Reading Test; MMSE, Mini-Mental State Examination; RBMT, Rivermead Behavioural Memory Test; EXIT, Executive Interview; FAS, Initial Letter Verbal Fluency Test. 
Table 3 Cognitive measures by community status

\begin{tabular}{|c|c|c|c|c|c|c|c|c|c|c|c|c|c|c|}
\hline \multirow[t]{2}{*}{ Community status ${ }^{4}$} & \multirow[t]{2}{*}{$n^{\prime}$} & \multirow[t]{2}{*}{ Male/female ratio } & \multicolumn{2}{|c|}{ Age (years) } & \multicolumn{2}{|c|}{ NART IQ } & \multicolumn{2}{|c|}{ MMSE $^{2}$} & \multicolumn{2}{|c|}{$\mathrm{RBMT}^{2}$} & \multicolumn{2}{|c|}{$\mathrm{EXIT}^{3}$} & \multicolumn{2}{|c|}{$\mathrm{FAS}^{2}$} \\
\hline & & & Mean & (s.d.) & Mean & (s.d.) & Mean & (s.d.) & Mean & (s.d.) & Mean & (s.d.) & Mean & (s.d.) \\
\hline In-patient (long-stay) & 15 & $6 / 9$ & 58 & (I8) & 92 & $(20)$ & 23 & (7) & 4 & (3) & 17 & (9) & 20 & (I5) \\
\hline In-patient (acute) & 9 & $7 / 2$ & 43 & (18) & 92 & $(14)$ & 26 & (3) & 5 & (3) & II & (6) & 21 & (9) \\
\hline Day-patient & 27 & $15 / 12$ & 41 & (13) & 98 & $(13)$ & 28 & (2) & 7 & (3) & II & (6) & 27 & (14) \\
\hline Out-patient & 48 & $28 / 20$ & 43 & (13) & 99 & (II) & 27 & (3) & 7 & (3) & 9 & (6) & 25 & $(12)$ \\
\hline $\begin{array}{l}\text { Community psychiatric } \\
\text { nurse care }\end{array}$ & 23 & $12 / 11$ & 55 & (13) & 97 & $(15)$ & 25 & (5) & 6 & (3) & 13 & (7) & 21 & $(12)$ \\
\hline $\begin{array}{l}\text { General practitioner } \\
\text { care }\end{array}$ & 16 & $5 / 11$ & 59 & (I7) & 107 & $(12)$ & 26 & (4) & 8 & (3) & 12 & (7) & 23 & $(12)$ \\
\hline
\end{tabular}

I. $n$ in different groups for different tests varies slightly, as not all patients completed all tests (see Table I).

2. The lower the score, the greater the impairment.

3. The higher the score, the greater the impairment.

4. ANOVA results by community status: MMSE: $F=4.15$, d.f. $=5, P=0.002 ;$ RBMT: $F=3.73$, d.f. $=5, P=0.003 ;$ EXIT: $F=2.88$, d.f. $=5, P=0.02$.

NART, National Adult Reading Test; MMSE, Mini-Mental State Examination; RBMT, Rivermead Behavioural Memory Test; EXIT, Executive Interview; FAS, Initial Letter Verbal Fluency Test.

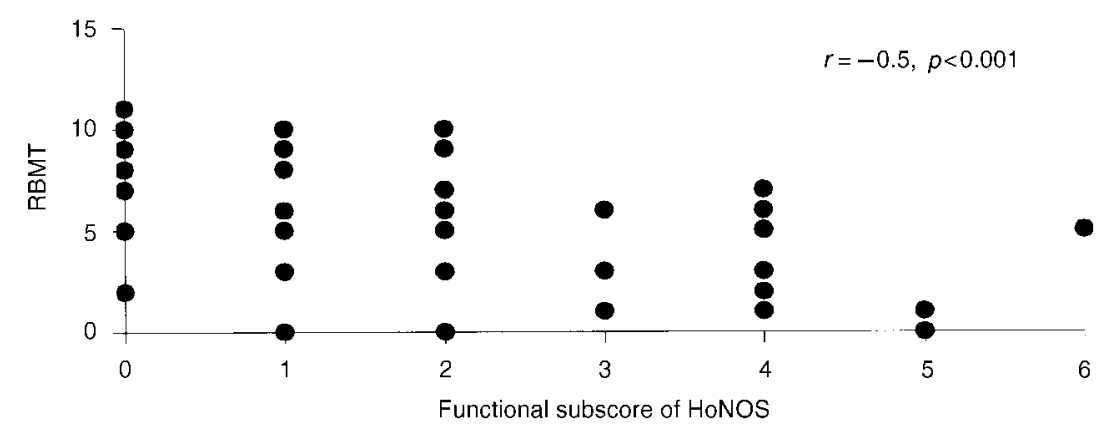

Fig. 2 Relationship between memory impairment (Rivermead Behavioural Memory Test (RBMT) screening score) and disability on functional impairment sub-scale of Health of the Nation Ouctome Scales (HoNOS).

60 patients with schizophrenia from acute, rehabilitation and long-stay services; in addition, similar proportions of patients in both studies are classed as having global cognitive impairment on the MMSE.

The numbers of patients with frontal dysfunction, as estimated by the FAS initial letter verbal fluency test (49\%), were double those obtained using the EXIT interview $(25 \%)$. Cut-off points, of course, are arbitrary. Also, the FAS is a timed test; poor performance by people with schizophrenia may be due to other factors, such as slowness or current psychotic symptoms, including thought disorder. The EXIT is designed for elderly or brain-damaged patients and allows for poor concentration and motivation.

\section{When does cognitive decline occur?}

There is much debate about when cognitive decline occurs in schizophrenia, and whether it is progressive or static. Some studies suggest that deficits in intellectual function are lifelong and pre-date (and may predispose to) the onset of schizophrenia (Russell et al, 1997). Other studies, which have examined first-episode, drugnaïve patients, reported clear neuropsychological deficits similar to those found in more chronic medicated patients (Scottish Schizophrenia Research Group, 1987). It has also been suggested that after a period of initial deterioration early in the illness, cognitive deficits become static (Hyde et $a l, 1994)$. Finally, it has been suggested that as schizophrenia becomes more severe and chronic, impairment becomes more widespread and clearly detectable, and amounts to dementia in some individuals (Scully et al, 1997).

While we should be cautious about making longitudinal interpretations of cross-sectional studies, the Nithsdale results suggest that older people (over 60 years of age) with schizophrenia show a poorer cognitive performance than younger patients. Our results are in direct contrast to those of Hyde et al (1994), who, in a cross-sectional study, reported no decline in cognitive function across five 10-year age cohorts (20-70 years). The apparent difference may be explained by the difference between the two groups studied: our study represents a whole population of patients, while Hyde and colleagues examined a highly selected group (522 screened to yield 74), from which patients who had conditions which might have an adverse impact on the central nervous system were excluded. In a recent shortterm (30-month) follow-up of geriatric long-stay patients with schizophrenia, cognitive and functional decline was detected (Harvey et al, 1999).

The mechanism underlying poor cognition in schizophrenia is unclear, and most work has failed to indicate a specific schizophrenic pathological process. However, many of the exclusion criteria employed by Hyde et al (1994) included comorbidity and treatments (such as substance misuse and hypertension, and electroconvulsive therapy) that are 
intimately associated with the schizophrenic illness process. These, as well as poor physical health and heavy cigarette smoking (Kelly \& McCreadie, 1999), may contribute to a premature aging process that can lead to earlier and accelerated cognitive decline.

\section{Cognition and community functioning}

The long-stay in-patient group clearly performed worse on all cognitive measures than did patients of a similar age in contact only with their family doctor. This finding is in keeping with previous studies which have examined large groups of chronic inpatients (Owens \& Johnstone, 1980).

While there has been much discussion about the range and nature of cognitive deficits, there has been less emphasis on their functional consequences. We used the HoNOS to assess community functioning. The HoNOS has recently been the subject of intensive scrutiny (British Journal of Psychiatry, 1999, 174, 380-438). It is not without its defects, but is gaining a place as another symptom and social function inventory, "better than most" (Stein, 1999). Our study showed a clear relationship between the functional impairment sub-scale of HoNOS and poor performance on current cognitive measures. The functional sub-scale is an assessment of problems in the community caused by poor cognition (memory, orientation and understanding) and physical illness or disability. The consequences of cognitive deficits were severe enough to be detected in a routine clinical setting by keyworkers, mainly community psychiatric nurses.

We conclude that cognitive dysfunction is a core disability in schizophrenia, affecting the majority of patients. Neuropsychological evaluation is rarely used in planning rehabilitation, yet cognitive deficits are likely to be a limiting factor in terms of functioning as a member of the community. If there is greater awareness of the prevalence and pervasiveness of cognitive dysfunction in schizophrenia and the ensuing disabilities, we may be able to help our patients function more effectively in the community. In Nithsdale we are now trying to engage some of our patients in cognitive remediation, a technique which, applied in schizophrenia, is in its infancy (O'Carroll et al, 1999).

\section{CLINICAL IMPLICATIONS}

- Cognitive dysfunction, particularly memory impairment, is a widespread and core disability in the majority of patients with schizophrenia.

- Cognitive dysfunction has a major impact on patients' daily lives and is likely to limit their functioning in the community.

Cognitive evaluation and remediation should become important approaches in the management of patients with schizophrenia.

\section{LIMITATIONS}

The neuropsychological battery of tests was short.

- A cross-sectional design limits speculation about longitudinal cognitive decline.

- The Health of the Nation Outcome Scales assessment was only available for onethird of the subjects.

CIARA KELLY, MRCPsych, Academic Department, Gartnavel Royal Hospital, Glasgow; VAL SHARKEY, RMN GARY MORRISON, MRCPsych, JUDITH ALLARDYCE, MRCPsych, and ROBIN G. MCCREADIE, DSc, Crichton Royal Hospital, Dumfries, Scotland

Correspondence: Professor R. G. McCreadie, Director of Clinical Research, Crichton Royal Hospital, Dumfries DGI 4TG, Scotland. Tel: 01387 244000; fax: 01387 257735; e-mail: rgmccreadie_crh@compuserve.com

(First received 13 October 1999, final revision 20 March 2000, accepted 12 April 2000)

\section{ACKNOWLEDGEMENTS}

We thank the patients in Nithsdale for their continuing cooperation; Heather Barrington for statistical advice; and Mary Muirhead and Susan Farrington for administrative support.

\section{REFERENCES}

Berg, A. (1948) A simple objective test for measuring flexibility in thinking. Journal of General Psychology, 39, $15-22$.

Crawford, J. R., Besson, J. A. O., Bremner, M., et al (1992) Estimation of premorbid intelligence in schizophrenia. British Journal of Psychiatry, 161, 69-74.

_, Obonsawin, M. C. \& Bremner, M. (1993) Fronta lobe impairment in schizophrenia: relationship to intellectual functioning. Psychological Medicine, 23 787-790.

Folstein, M. F., Folstein, S. E. \& McHugh, P. R. (1975) "Mini-mental State": a practical method for grading the cognitive state of patients for the clinician. Journal of Psychiatric Research, 12, 189-198.

Frith, C. D., Leary, J., Cahill, C., et al (199I) IV. Performance on psychological tests: demographic and clinical correlates of the results of these tests. British Journal of Psychiatry, 159 (suppl. 13), 26-29.

Goldberg, T. E., Weinberger, D. R., Berman, K. F., et al (1987) Further evidence for dementia of prefronta type in schizophrenia? A controlled study of teaching the Wisconsin Card Sorting Test. Archives of General Psychiatry, 44, 1008-1014.

_ , Greenberg, R. D., Griffin, S. J., et al (1993) The effect of clozapine on cognition and psychiatric symptoms in patients with schizophrenia. British Journa of Psychiatry, 162, 43-48.

Green, M. F. (1996) What are the functiona consequences of neurocognitive deficits in schizophrenia? American Journal of Psychiatry, 153 $321-330$.

Harvey, P. D., White, L., Parrella, M., et al (1995) The longitudinal stability of cognitive impairment in schizophrenia. Mini-Mental State Scores at one- and two-year follow-ups in geriatric in-patients. British Journal of Psychiatry, 166, 630-633.

Silverman, J. M., Mohs, R. C., et al (1999)

Cognitive decline in late-life schizophrenia: a longitudinal study of geriatric chronically hospitalised patients. Biological Psychiatry, 45, 32-40.

Hyde, T. M., Nawroz, S., Goldberg, T. E., et al (1994) Is there cognitive decline in schizophrenia? A crosssectional study. British Journal of Psychiatry, 164 , 494-500.

Kelly, C. \& McCreadie, R. G. (1999) Smoking habits, current symptoms, and premorbid characteristics of schizophrenic patients in Nithsdale, Scotland. American journal of Psychiatry, 156, 175I-1757. 
_, _, MacEwan, T., et al (1998) Nithsdale Schizophrenia Surveys 17: Fifteen year review. British Journal of Psychiatry, 172, 513-517.

Liddle, P. F. \& Crow, T. J. (1984) Age disorientation in chronic schizophrenia is associated with global intellectual impairment. British Journal of Psychiatry, 144 193-199.

McCreadie, R. G. (1982) The Nithsdale Schizophrenia Survey: I. Psychiatric and social handicaps. British Journal of Psychiatry, 140, 582-586.

_ , Leese, M., Tilak-Singh, D., et al (1997) Nithsdale, Nunhead and Norwood: similarities and differences in prevalence of schizophrenia and utilisation of services in rural and urban areas. British Journal of Psychiatry, 170, $31-36$.

McGuffin, P., Farmer, A. E. \& Harvey, I. (1991) A polydiagnostic application of operational criteria in studies of psychotic illness: development and reliability of the OPCRIT system. Archives of General Psychiatry, 48, 764-770.

McKenna, P. J., Tamlyn, D., Lund, C. E., et al (1990) Amnesic syndrome in schizophrenia. Psychological Medicine, 20, 967-972.

Nelson, H. E. (1982) National Adult Reading Test. Test Manual.Windsor, UK: NFER-Nelson.
O'Carroll, R. E., Russell, H. H., Lawrie, S. M., et al (1999) Errorless learning and the cognitive rehabilitation of memory-impaired schizophrenic patients. Psychological Medicine, 29, 105-112.

Owens, D. G. C. \& Johnstone, E. C. (1980) The disabilities of chronic schizophrenia - their nature and the factors contributing to their development. British Journal of Psychiatry, I36, 384-395.

Parker, D. M. \& Crawford, J. R. (1992) Assessment of frontal lobe dysfunction. In Handbook of

Neuropsychological Assessment (eds J. R. Crawford,W. McKinlay \& D. M. Parker), pp. 267-291. Hove: Erlbaum and Associates.

Royall, D. R., Mahurin, R. K. \& Gray, K. F. (1992)

Bedside assessment of executive cognitive impairment.

The Executive Interview. Journal of the American Geriatric Society, 40, $1221-1226$

Russell, A. J., Munro, J. C., Jones, P. B., et al (1997) Schizophrenia and the myth of intellectual decline. American Journal of Psychiatry, 154, 635-639.

Saykin, A. J., Gur, R. C., Mozley, P. D., et al (1991)

Neuropsychological function in schizophrenia: selective impairment in memory and learning. Archives of General Psychiatry, 48, 618-624.
Scottish Schizophrenia Research Group (1987) Scottish first episode schizophrenia study. III. Cognitive performance. British Journal of Psychiatry, 150, 338-340.

Scully, P. J., Coakley, G., Kinsella, A., et al (1997) Executive (frontal) dysfunction and negative symptoms in schizophrenia: apparent gender differences in 'static' $v$. 'progressive' profiles. British Journal of Psychiatry, I7I 154-158.

Stein, G. S. (1999) Usefulness of the Health of the Nation Outcome Scales. British Journal of Psychiatry, 174 375-377.

Wechsler, D. (198I) WAIS-R Manual. New York, NY: Psychological Corporation.

Wilson, B. A., Cockburn, J. M., Baddely, A. D., et al (1989) The development and validation of a test battery for detecting and monitoring everyday memory problems. Journal of Clinical and Experimental Neuropsychology, II, 855-870.

Wing, J. K., Beevor, A. S., Curtis, R. H., et al (1998) Health of the Nation Outcome Scales (HoNOS) Research and development. British Journal of Psychiatry, I72, $\mid 1-18$.

World Health Organization (1992) The ICD-10 Classification of Mental and Behavioural Disorders. Geneva: World Health Organization. 